\title{
Efeitos da gestão do "Bolsa Família" no cotidiano de mulheres quilombolas rurais
}

\author{
Antonio Alves Filho ${ }^{1, *}$, Magda Dimenstein ${ }^{2}$, Victor Hugo Belarmino ${ }^{3}$, \\ Jáder Ferreira Leite, Candida Dantas ${ }^{5}$, João Paulo Macedo ${ }^{6}$
}

${ }^{1}$ http:/ / orcid.org/0000-0001-8370-1096 / Universidade Federal do Rio Grande do Norte (UFRN), Brasil
${ }^{2}$ http:/ / orcid.org/0000-0002-5000-2915 / Universidade Federal do Rio Grande do Norte (UFRN), Brasil
${ }^{3}$ http:/ / orcid.org/0000-0002-4102-3351 / Universidade Federal do Rio Grande do Norte (UFRN), Brasil
${ }^{4}$ http:/ / orcid.org/0000-0002-6045-531X / Universidade Federal do Rio Grande do Norte (UFRN), Brasil
${ }^{5}$ http://orcid.org/0000-0003-4778-9400 / Universidade Federal do Rio Grande do Norte (UFRN), Brasil
${ }^{6}$ http://orcid.org/0000-0003-4393-8501 / Universidade Federal do Delta do Parnaíba (UFDPAR), Brasil

Resumo

As mulheres se destacam na gestão do Bolsa Família. Essa condição tem produzido deslocamentos nas relações de gênero, bem como no trabalho em contextos rurais. A respectiva pesquisa buscou investigar as formas de gestão do Bolsa Família, analisando seus efeitos no cotidiano de setenta e duas mulheres, moradoras de duas comunidades quilombolas, por meio de entrevistas semiestruturadas. O benefício tem sido usado para atender às condicionalidades em relação aos filhos e à manutenção da família. Entretanto, foi possível constatar que as mulheres suprem outras necessidades domésticas e pessoais. Observa-se que, para além da complementação da renda familiar, o benefício tem impactado na diminuição da sobrecarga de trabalho doméstico e no campo, na ampliação da segurança alimentar e da mobilidade, bem como na mudança de padrões familiares e de gênero estabelecidos. Tais aspectos apontam para a ampliação dos graus de autonomia identificados pelas próprias participantes no seu dia-a-dia, reverberando em novos modos de vida e de trabalho distintos.

Palavras-chave: programa bolsa família, mulheres quilombolas, cotidiano.

\section{Effects of "Bolsa Família" management on daily life of rural Quilombola women}

Abstract

Women stand out in the management of the Bolsa Família. This has produced displacements in gender relations and work in rural contexts. This research investigated the forms of management of the Bolsa Família and analyzed its effects on the daily lives of 72 women living in two Quilombola communities, through semi-structured interviews. Bolsa Família has been used to meet conditions in relation to children, and maintenance of the family. However, women tend to other domestic and personal needs. It can be observed that, in addition to complementing family income, the benefit has had an impact in reducing the burden of domestic and field work, in increasing food security and mobility, as well as in changing established family and gender patterns. These aspects point to the expansion of the degrees of autonomy identified by the participants themselves in their daily lives, reverberating in different ways of living and working.

Keywords: "Bolsa Família” program, Quilombola women, daily life.
Efectos de la gestión de lo "Bolsa Família" en la vida cotidiana de mujeres quilombolas rurales

Resumen

Las mujeres se destacan en la gestión de lo Bolsa Família. Esta condición ha producido desplazamientos en las relaciones de género, bien como en el trabajo en contextos rurales. La respectiva investigación buscó investigar las formas de gestión de la Bolsa Família y analizó sus efectos en la vida cotidiana de 72 mujeres que vivían en dos comunidades quilombolas, a través de entrevistas semiestructuradas. La prestación se ha utilizado para cumplir las condiciones en relación con los hijos y el mantenimiento de la familia. Sin embargo, fue posible constatar que las mujeres satisfacen otras necesidades domésticas y personales. Puede observarse que, además de complementar los ingresos familiares, el beneficio ha tenido repercusiones en la reducción de la carga del trabajo doméstico y sobre el terreno, en el aumento de la seguridad alimentaria y la movilidad, así como en la modificación de las pautas familiares y de género establecidas. Tales aspectos apuntan a la expansión de los grados de autonomía identificados por los propios participantes en su vida cotidiana, que repercuten en las nuevas y diferentes formas de vivir y trabajar.

Palabras-claves: programa "Bolsa Família", mujeres quilombolas, cotidiano. 
No Brasil, a titularidade do benefício do Programa Bolsa Família (PBF) é, em quase sua totalidade, das mulheres que, além de gerenciarem o recurso na família, são também as responsáveis por garantir o cumprimento das condicionalidades. Esse lugar de destaque nos programas de transferência de renda tem produzido deslocamentos nas relações de gênero nos contextos familiares e comunitários, impactado na participação política, além de operar mudanças nos modos de trabalho no meio rural (Bartholo, Passos, \& Fontoura, 2019). Deste modo, pretendemos neste artigo analisar as formas de gestão do Bolsa Família empreendidas por mulheres quilombolas rurais, moradoras de duas comunidades, uma no Rio Grande do Norte e outra no Piauí e conhecer em que medida o PBF programa afeta seu cotidiano em diferentes dimensões, em particular, as atividades laborais que desempenham, as relações familiares e comunitárias e os gradientes de autonomia feminina.

O Programa Bolsa Família (PBF), instituído em 2004 através da lei no 10.836, consiste em um Programa de Transferência Condicionada (PTC) de renda, o qual faz parte de uma estratégia ampla de proteção social impulsionada pelo Estado brasileiro: o Plano Brasil sem Miséria, instituído em 2013. Ao unificar os programas Bolsa Escola, Bolsa Alimentação e Auxílio-Gás, o Bolsa Família se torna o programa social com maior capilaridade nacional, abrangendo todos os municípios e o maior PTC da América Latina (Arrais, 2016).

Os estudos e pesquisas envolvendo o PBF, em geral, têm demonstrado que esse programa tem obtido efeitos positivos em termos de segurança alimentar, saúde, frequência e progressão escolar das crianças, bem como na redução da evasão escolar, da mortalidade infantil e do trabalho infantil (Ribeiro, Shikida, \& Hillbrecht, 2017). Para além dos resultados já esperados pelo programa, passados pouco mais de 15 anos desde sua institucionalização, amplia-se o interesse e a relevância de seus 'efeitos colaterais', que envolvem aspectos não esperados como o aumento do registro civil, acesso ao sistema financeiro e, tal como no presente artigo, em outras dimensões da vida, como o trabalho, as relações familiares e nos gradientes de autonomia feminina (Bartholo et al., 2019; Ribeiro et al., 2017).

No entanto, ainda são escassos os estudos de caráter qualitativo que avaliem os efeitos do programa. Aqueles que fazem uso das pesquisas amostrais e censitárias elaboradas pelos órgãos de pesquisa do governo federal - principalmente as PNADs e o Censo demográfico - são os mais frequentes, o que pode se converter em um artifício homogeneizador e limitado, se considerarmos as dimensões continentais do Brasil e sua diversidade geográfica e populacional. Ademais, predomina o interesse pelo estudo dos efeitos do PBF em termos de segurança alimentar/nutricional e indicadores educacionais (M. C. S. Santos, Delatorre, Ceccato, \& Bonolo, 2019; Wolf \& Barros, 2014), especialmente de crianças e adolescentes.

Contudo, os impactos do programa na vida cotidiana das mulheres beneficiárias, sobretudo, na questão do trabalho, são menos investigados, havendo uma clara tendência nos estudos existentes em considerá-lo sinônimo de entrada no mercado formal de trabalho, seja por homens ou mulheres, seja morador(a) do campo ou da cidade, tomados de forma homogênea. Desse modo, nota-se o foco em uma hermenêutica centrada no urbano, desconectada da problemática de gênero, bem como das condições sob as quais o trabalho é desempenhado pelas mulheres rurais no Brasil (Dimenstein, Leite, Macedo, \& Dantas, 2016).

Nessa direção, reconhecemos que os contextos rurais têm particularidades no agenciamento de certos modos de vida e trabalho (Maciazeki-Gomes, Nogueira, Vázquez, \& Toneli, 2016); remetem à uma outra temporalidade e ritmo de trabalho, instituídos pelo corpo, pelas condições climáticas e formas de relação com o espaço (Diniz, 2017; Fernandes \& Mota, 2014). São marcados por estratégias de ação produtiva que respondem a fatores para além do econômico, como as relações culturais, socio afetivas, de solidariedade/reciprocidade, relações não-mercantis inter/intrafamiliares e normas sociais tradicionalmente repassadas (Diniz, 2017; Neri \& Garcia, 2017). Por fim, resistem à subordinação do trabalho ao seu valor de troca, à transformação da mão de obra camponesa em mera mercadoria e defendem a preservação de um modo de vida e trabalho de natureza comunitária, solidária e de vizinhança. Em razão dessas particularidades, nos interrogamos acerca da gestão do PBF nesse cenário e seus efeitos em variadas dimensões da vida das mulheres beneficiárias, dentre elas, o trabalho.

Por outro lado, em se tratando de comunidades quilombolas, é impossível desconsiderar as questões de raça/etnia e não reconhecer que no Brasil a pobreza tem cor - e é negra (Rego \& Rego, 2013). A última síntese dos indicadores sociais lançada pelo Instituto Brasileiro de Geografia e Estatística (IBGE, 2018) indicou que as pessoas pretas ou pardas desempenham as atividades com menores rendimentos, independentemente do nível de escolaridade; apresentam maiores taxas de desocupação e de ocupações informais; bem como as menores taxas de rendimento domiciliar per capita; possuem maiores índices de restrições em múltiplas dimensões do acesso à educação, à proteção social, à moradia adequada, aos serviços de saneamento básico e à comunicação. Revela ainda que a pobreza não só tem cor, como também tem gênero: as mulheres ganham menos que os homens, mesmo que desempenhem as mesmas funções ou tenham maiores níveis de escolaridade, sendo os afazeres domésticos e o cuidado de filhos ou de outros parentes um fator determinante para não assumirem trabalhos remunerados. Todos esses dados variam regionalmente, apresentando índices problemáticos para o Nordeste, região onde pertencem as duas comunidades investigadas.

As iniquidades sofridas pelas mulheres negras estão profundamente ancoradas à história social da escravidão no Brasil, a qual articula gênero e raça. A escravidão, instituição plurissecular, produziu não só uma abissal desigualdade na distribuição de renda, de riqueza e oportunidades, mas práticas sociais e políticas de exclusão e dominação (Rego \& Rego, 2013). A hierarquia racial e de gênero constituída através da "colonialidade do poder trabalho” (Bernardino-Costa, 2015, p. 150), ainda não superada, mantém a divisão racial do trabalho desde os tempos coloniais até o presente. Além disso, Pinheiro e Maia (2017) destacam que o corpo da mulher negra experimentou a escravidão de modo diferenciado: um corpo inscrito no espaço doméstico, o qual servia também à exploração de suas funções reprodutivas e sexuais.

Portanto, não é forçoso observar, tal como aludem Rego e Rego (2013), certa continuidade do estereótipo do negro escravo preguiçoso nos discursos que responsabilizam o pobre pela sua própria miséria. Segundo esses autores, no caso brasileiro, isso se materializa nas acusações de que os beneficiários de programas como o Bolsa Família preferem viver desse recurso, em vez de trabalhar; de fazer filhos para ganhar mais dinheiro do Estado, estereótipos marcados por questões morais e de classe, bem como pela desinformação sobre o sentido do programa e por premissas neoliberais como a meritocracia.

Assim, aproximar-se do cotidiano das mulheres beneficiárias do PBF e investigar as repercussões da transferência de renda nas suas condições de vida, no trabalho e autonomia, especialmente de mulheres quilombolas rurais, cujas singularidades ainda estão por ser melhor conhecidas, reveste-se de importância, ainda mais no cenário atual de desmonte das políticas públicas no país e de retrocessos na promoção da equidade de gênero. É na perspectiva de contribuir nessa direção que o presente artigo se propõe a apresentar parte dos resultados de uma pesquisa mais ampla que versa sobre autonomia, gestão do cotidiano e modos de vida de mulheres beneficiárias do Programa Bolsa Família, dando destaque 
aos efeitos produzidos pelo recebimento do benefício em algumas dimensões das suas vidas, em particular, no âmbito do trabalho.

\section{Método}

Trata-se de um estudo com delineamento qualitativo, de natureza descritivo-exploratória. Enquanto tal, toma o "social como um mundo de significados passível de investigação" (Minayo \& Sanches, 1993, p. 242) e ancora-se no compromisso com a abertura de vias de problematização das relações sociais estabelecidas, com a decomposição e recomposição de sentidos e práticas no cotidiano. Em função disso, inúmeros desafios foram vivenciados em campo, sendo necessário afinar nossa capacidade de identificar e compreender as particularidades e singularidades de cada comunidade pesquisada, da história de cada uma das mulheres, fazer escolhas quanto aos procedimentos de entrada nos territórios e em relação aos instrumentos e formas de análise condizentes com essa perspectiva epistemológica e metodológica. Esses desafios foram amplamente discutidos por Dantas, Dimenstein, Leite, Macedo e Torquato (2018).

\section{Participantes}

A pesquisa foi realizada em duas comunidades quilombolas. A comunidade situada na zona rural do município de Bom Jesus, no estado do Rio Grande do Norte, abrange 140 famílias. O processo de identificação e reconhecimento da comunidade pela Fundação Cultural Palmares ocorreu em 2003. Todavia, diferentemente da outra comunidade, não recebeu, até a ocasião da pesquisa, a titularidade das terras. Por sua vez, a comunidade quilombola, localizada na zona rural do município de Esperantina, no Piauí, é composta por 87 famílias. Em 2005, a comunidade foi reconhecida e certificada pela Fundação Cultural Palmares, e em 2006, obteve a titulação da terra, expedida pelo Instituto Nacional de Colonização e Reforma Agrária (INCRA) em parceria com o Instituto de Terras do Piauí (INTERPI). As 72 participantes de nossa pesquisa foram mulheres beneficiárias do PBF, moradoras dessas comunidades, sendo 37 no RN e 35 no PI. Apresentam idades entre 18 e 59 anos (maior percentual na faixa dos 30 aos 39 anos - 40\%). Majoritariamente são casadas (72\%), formam famílias com 3 a 4 membros (58\%), declaram religião católica $(92 \%)$ e possuem até o ensino fundamental (completo ou incompleto $-53 \%$ ) ou ensino médio (completo ou incompleto $-37 \%$ ).

\section{Instrumentos}

Valorizamos a perspectiva da triangulação metodológica e insistimos na complementariedade de ferramentas que valorizam a compreensão dos complexos processos subjetivos e simbólicos de forma contextualizada. Assim, a produção dos dados da pesquisa ampliada foi orientada por um questionário sociodemográfico, um roteiro de entrevista semiestruturado e pela observação participante. Utilizamos parte desse questionário para o delineamento do perfil das participantes. O restante dos dados aqui apresentados são frutos das entrevistas, que foram literalmente transcritas, parte delas aqui apresentadas. Especificamente sobre o eixo trabalho e gestão do PBF, investigou-se os seguintes aspectos: (1) atividades cotidianas desempenhadas pelas mulheres; (2) formas de complementação da renda; (3) modos de gestão e utilização do recurso do BF e (4) impactos do BF na dinâmica de vida dessas mulheres.

\section{Procedimentos de Coleta de Dados e Cuidados Éticos}

O contato com as comunidades ocorreu por meio de suas lideranças e da participação em assembleia nas associações comunitárias, quando foi obtida autorização para a realização da pesquisa. A etapa de campo, ocorrida em 2018 e 2019, contou com o auxílio e acompanhamento de 'guias', moradores das comunidades, os quais viabilizaram o acesso às potenciais colaboradoras e à realização da coleta de dados, que foi feita nas casas das participantes, confirmando uma amostragem por conveniência. Em se tratando de uma pesquisa de natureza qualitativa, que não tinha como meta a realização de análises estatísticas, nem a construção de um tipo de amostragem que produzisse análises probabilísticas ou inferenciais, nem intencionava efeitos comparativos entre os dois estados, optamos por entrevistar o maior número de mulheres que se disponibilizasse a participar, desde que cumprissem o critério de terem oficialmente a titularidade do BF. Nesse sentido, a colaboração dos guias comunitários foi decisiva, pois conheciam cada uma das mulheres que atendiam a esse critério. No primeiro encontro foram tratados aspectos éticos, tais como: assinatura do termo de consentimento para participação da pesquisa, autorização para gravação de voz e garantia de sigilo.

\section{Procedimentos de Análise de Dados}

O tratamento dos dados foi feito a partir da análise de conteúdo, na modalidade Análise Temática (Minayo, 2010), procedendo os seguintes passos: 1) transcrição integral das entrevistas; 2) categorização dos conteúdos de acordo com os seguintes eixos de análise: (a) atividades cotidianas desempenhadas pelas mulheres; (b) formas de complementação da renda familiar; (c) modos de gestão e utilização do recurso do BF e (d) impactos do BF na dinâmica de vida dessas mulheres; 3) Revisão coletiva das categorias sínteses de análise; 4) Discussão teórica dos resultados.

\section{Resultados}

Após a primeira categorização dos dados, os eixos de análise foram desdobrados e os conteúdos reorganizados nas subcategorias expostas na Tabela 1.

\section{Discussão}

\section{Atividades Laborais e Renda das Mulheres Quilombolas}

Identificar as atividades desempenhadas pelas mulheres no cotidiano foi o elemento disparador de uma reflexão que intencionava problematizar se o recebimento do BF impactava ou não na realização dessas tarefas, se o benefício era suficiente ou não para atender às necessidades da família, de que forma manejavam o recurso e se elas observavam alterações nas suas vidas a partir do recebimento do mesmo.

De acordo com os resultados apresentados, as principais atividades referidas pelas mulheres dos dois estados são as domésticas, de cuidado da família e a agricultura/pecuária, as quais estão intimamente relacionadas. No contexto rural, geralmente, se observa uma extensão ou continuidade das atividades desenvolvidas no espaço da casa - e as relações que nela se estabelecem - com o quintal e o roçado (Alves, 2014; Montenegro \& Leiva, 2017; Paulilo, 2016). O trabalho doméstico abarca tanto as atividades desempenhadas na própria residência, quanto as funções de faxineiras em outras residências. Os afazeres domésticos envolvem desde a preparação das refeições, costura, limpeza, organização da casa e do quintal, até a alimentação dos animais de pequeno e 


\begin{tabular}{|c|c|c|c|}
\hline Eixos Temáticos & Piauí & Rio Grande do Norte & Total \\
\hline \multicolumn{4}{|l|}{ Atividades cotidianas desempenhadas pelas mulheres } \\
\hline Afazeres domésticos & 25 & 32 & 57 \\
\hline Trabalho na agricultura/pecuária/extrativismo & 26 & 18 & 44 \\
\hline Cuidado dos filhos e/ou familiares & 15 & 16 & 31 \\
\hline Atividades informais e na associação comunitária & 8 & 2 & 10 \\
\hline Trabalho remunerado & 1 & 8 & 9 \\
\hline Atividades de lazer & 0 & 1 & 1 \\
\hline \multicolumn{4}{|l|}{ Formas de complementação da renda familiar } \\
\hline Venda de produtos agropecuários & 19 & 13 & 32 \\
\hline Renda do (ex)companheiro e/ou contribuição de familiares & 8 & 11 & 19 \\
\hline Prestação de serviços & 1 & 7 & 8 \\
\hline Comércio de produtos variados & 7 & 3 & 10 \\
\hline Outros programas sociais & 2 & 2 & 4 \\
\hline \multicolumn{4}{|l|}{ Modos de gestão e utilização do recurso do BF } \\
\hline Alimentação da família & 32 & 29 & 61 \\
\hline Despesas com os filhos & 21 & 20 & 41 \\
\hline Manutenção da casa & 9 & 13 & 22 \\
\hline Utensílios de uso pessoal & 6 & 6 & 12 \\
\hline Tratamento/Remédios & 5 & 7 & 12 \\
\hline Poupança & 2 & 1 & 3 \\
\hline Manutenção da moto & 0 & 1 & 1 \\
\hline \multicolumn{4}{|l|}{ Impactos do BF na vida das mulheres } \\
\hline Dinâmica familiar e relações conjugais & 11 & 26 & 37 \\
\hline Poder de decisão & 14 & 12 & 26 \\
\hline Acesso a bens de consumo & 9 & 3 & 12 \\
\hline Sente-se mais valorizada & 1 & 1 & 2 \\
\hline
\end{tabular}

médio porte, como galinhas e cabras. A maior parte dessas mulheres avalia o trabalho doméstico de forma positiva, como uma oportunidade de contribuir com a organização familiar e uma renda extra como no caso das diaristas. Por outro lado, muitas dessas mulheres reconhecem as atividades domésticas como um trabalho repetitivo, rotineiro, cansativo e restrito ao espaço privado da casa.

Às vezes quando a gente cai na rotina é ruim, viu? Aí todo dia cozinhar feijão, varrer casa, lavar louça, cuidar dos bichos, entendeu? Aí vira rotina, mas é bom! Tem que ir tocando a vida pra frente desse jeito mesmo. Agora se tivesse assim, por exemplo, "hoje eu tô de folga, ô coisa boa, hoje eu vou dar uma geral na minha casa, vou fazer uma faxina, porque amanhã eu vou ter um curso pra ir fazer" ou "rapaz, depois de amanhã, olha, tem um curso de crochê pra mim ir, depois tem um de informática" entendeu? Tinha que quebrar mais um pouquinho essa rotina da dona de casa tá todo dia fazendo aquela mesma coisa. Todo dia: limpa casa, cuida de animal, faz comer pra cachorro, lava roupa, entendeu? Vira rotina (Entrevistada 35, 53 anos, RN).

Essa rotina faz com que muitas vezes questionem o lugar de donas de casa, que se sintam frequentemente indispostas e até mesmo se sintam impelidas ao consumo abusivo de álcool. Pesquisa anterior acerca do consumo de álcool em comunidades quilombolas confirma esse dado e aponta que, entre as mulheres, o uso do álcool tem sido fortemente utilizado como recurso para a resolução de problemas e o enfrentamento das precárias condições de vida e da sobrecarga de trabalho, incluindo a rotina e a repetição de tarefas (Dimenstein et al., 2018).

A conformação das mulheres para a domesticidade é, evidentemente, efeito das desigualdades e assimetrias de poder entre os gêneros (Silva, Luz, Cezar-Vaz, \& Silva, 2012). De acordo com Biroli (2015), “a domesticidade tem tido uma função ideológica de sucesso: a naturalização da responsabilização prioritária das mulheres pelo trabalho doméstico e pelo cuidado dos familiares, especialmente das crianças. Como tal, atravessa diferentes classes sociais" (p. 92). Apesar de serem atividades fundamentais à existência humana e demandar tempo e disciplina para sua execução, aquelas desenvolvidas no espaço doméstico marcam as divisões de gênero, posto que persiste o discurso da mulher como responsável pelas atividades do lar e da participação masculina como 'ajuda' e não como trabalho. Assim, "o trabalho que as mulheres realizam na vida cotidiana doméstica, na sua forma e no tempo que é a ele dedicado, está longe de ser uma escolha voluntária" (Biroli, 2015, p. 90). Ademais, o trabalho doméstico continua sendo desqualificado e desvalorizado enquanto "não trabalho" (Lago, Souza, Kaszubowski, \& Soares, 2009, p. 357) e, portanto, segue invisibilizado no espaço privado da casa. Isso tem implicações na qualidade de vida das mulheres 'donas de casa', uma vez que fatores como a rotina, a monotonia, poucas redes sociais e o baixo status do trabalho doméstico, aliados às precárias condições socioeconômicas, são apontados como importantes determinantes de saúde-adoecimento nesta população (Senicato, Lima, \& Barros, 2016).

Algumas mulheres, além das tarefas que executam em suas casas, desenvolvem trabalho doméstico remunerado (diaristas), especialmente no RN, como estratégia de complementação da renda. Nesses casos, é importante reconhecer a intersecção de gênero com as dimensões de raça e classe, complexificando a questão. Ou seja, em termos de discriminação racial, uma das heranças coloniais consiste na atribuição de trabalhos menos valorizados e mal ou não remunerados às pessoas negras (Quijano, 2005). As trabalhadoras domésticas têm sido um recurso indispensável à liberação das mulheres brancas de classe média dos afazeres da 
casa, possibilitando-as assumirem empregos de maior prestígio social (Biroli, 2018; Sorj, 2014). Ou ainda, na divisão dos afazeres domésticos, relegar às empregadas domésticas aquelas atividades que exigem maior esforço físico (Bernardino-Costa, 2015).

Ainda no âmbito doméstico, o cuidado dos filhos e de outros membros da família está fortemente atrelado à vida das mulheres. No caso dos filhos, abrange tarefas como arrumar para ir à escola e ajudar na lição de casa, "botar pra dormir", preparar refeições etc. Os filhos mais novos ou recém-nascidos demandam maior dedicação e esforço das mulheres, posto que na execução dessas tarefas, a participação do pai é referida somente como uma ajuda. Em relação às pessoas idosas e/ou com necessidade de acompanhamento em saúde, realizam atividades como levar ao médico, comprar e administrar as medicações:

Eu acho que meu papel na minha família mais é eu, porque minha mãe só é eu mulher, aí sou eu quem resolvo tudo pra ela, os outros tudo viaja fora, aí sou eu que faço alguma coisa pra minha mãe, resolvo, vou comprar remédio. Então me sinto, faço de tudo na minha família (Entrevistada 58, 35 anos, PI).

Historicamente, as mulheres são socializadas e ensinadas desde cedo a desempenhar a função de cuidadoras. Discursos fortemente arraigados atravessam a organização das famílias que tomam a mulher como naturalmente inclinadas ao cuidado (Alves, 2014; Sorj, 2014). Essas concepções reverberam no trabalho doméstico não remunerado, uma vez que é uma atividade desvalorizada e distribuída desigualmente entre homens e mulheres (Biroli, 2015). Ademais, nesse cenário, como apontam Fernandes e Mota (2014), mulheres com filhos pequenos permanecem mais tempo em casa, participam menos na gestão da renda familiar, bem como têm mais dificuldades em romper relações violentas, aprofundando as desigualdades de gênero.

Quando se trata das atividades na agricultura e pecuária, a relação trabalho/ajuda se inverte, indicando a divisão sexual do trabalho no meio rural: a maioria das mulheres entende que seu lugar é de suporte ao trabalho dos homens, apesar de realizarem as mesmas tarefas que eles, as quais abrangem desde a capinação, preparação da terra para o plantio, semeadura, acompanhamento do crescimento e aparecimento de pragas, até a colheita e manejo das vagens e manuseio de animais de grande porte (gado, cavalos). No caso específico da comunidade piauiense, as mulheres desempenham tarefas relativas ao extrativismo e beneficiamento do babaçu, abrangendo atividades como: coleta, quebra do coco de babaçu e fabricação de carvão a partir de sua casca, atividades que consomem grande parte do seu tempo diário.

Nesse âmbito, portanto, é notável os efeitos do padrão sexista que organiza o trabalho intrafamiliar, o qual coloca a mulher em posição de subordinação. Nesse sentido, a realidade das duas comunidades quilombolas corrobora o que foi relatado na literatura: à mulher é atribuído o papel de 'ajuda', mesmo quando ela trabalha mais ou tanto quanto o homem (Fernandes \& Mota, 2014) e o labor dispensado às criações, sobretudo, de animais de pequeno porte, são de cunho feminino (Chaves, Castro, \& Portugal, 2018). Esse padrão sexista opera segundo relações de gênero que desqualificam o trabalho realizado pelas mulheres, ou seja, o sexo de quem pratica a atividade, por si só, orienta práticas discursivas sobre o que seria considerado um trabalho 'leve', 'pesado', ou mesmo, 'complementar' (Neri \& Garcia, 2017; Paulilo, 2016).

Dessa forma, o trabalho das mulheres na agricultura e pecuária tem muita importância para a manutenção da família, mas tem status diferenciado em comparação ao dos homens. Mesmo assim, de acordo com algumas participantes, há muitos pontos positivos, pois permite o acesso a créditos para investir na agricultura familiar, se pode gerir o próprio tempo, funciona como importante fator de transmissão intergeracional de conhecimentos, reforçando vínculos culturais e não exige estudo formal para sua execução, levando-se em conta que a maioria têm baixos níveis de escolaridade. Segundo uma participante:

Me sinto bem, eu tô fazendo uma coisa que gosto. Porque assim, você trabalha em casa de família, nem todo dia a sua patroa tá de bom humor. Porque tem dia que a patroa trata você bem, tem dia que a patroa trata você mal, aí você tem que aguentar aquilo por quê? Porque você sabe que tem que manter a casa. Aí a gente aguenta porque tem filho pra sustentar, tem essas coisas. Hoje em dia eu tô trabalhando pra mim, eu vou pro roçado o dia que eu quero, a hora que eu quero, saio a hora que eu quero. $\mathrm{Na}$ casa dos outros a gente não faz isso, né? (Entrevistada 32, 44 anos, RN).

Nesse sentido, o trabalho na agricultura não é o "simples cumprimento do que seria um dever em virtude do matrimônio, que a une com o agricultor" (Montenegro \& Leiva, 2017, p. 32), mas consiste em importante vetor de subjetivação, produzindo efeitos de autonomia na vida dessas mulheres. Sair do contexto rotineiro da casa e ocupar outros espaços laborais como o roçado tem funcionado como um importante fator de proteção à saúde mental dessas mulheres. Ademais, viabiliza o recebimento de alguma remuneração com a comercialização dos produtos agropecuários e, especialmente, a gestão do próprio tempo.

Contudo, em termos das atividades laborais em geral, fica evidente a longa jornada dessas mulheres, que o cotidiano é marcado pela sobrecarga de trabalho, pelo acúmulo de diferentes atividades e responsabilidades como o cuidado de parentes e filhos, o trabalho doméstico e na agricultura, não existindo quase nenhum espaço para atividades de lazer, como pode ser visto nos resultados. Esse volume de tarefas é realizado em meio à precariedade de suporte por parte das políticas públicas, de vínculos empregatícios formais, de pouca autonomia financeira e baixos níveis de divisão de responsabilidades com os homens. Não por acaso, as mulheres de ambos os estados necessitam complementar a renda familiar, associando o recebimento do benefício com atividades de comércio de variados produtos, seja agropecuários, seja de produtos de beleza, com a prestação de serviços, com a ajuda financeira da família e o recebimento de benefícios advindos de outros programas sociais.

Sabemos que as relações de gênero assimétricas e desiguais atravessam as atividades laborais, produzindo efeitos diversos na vida de homens e mulheres. Quando as desigualdades étnico-raciais são levadas em conta, essa realidade ganha novos contornos, posto que as mulheres negras necessitam enfrentar outras barreiras como o racismo institucional, a negação de sua ancestralidade e do direito à terra. Dessa forma, é importante relembrar que as experiências das mulheres negras não são redutíveis à categoria universal e essencializada 'mulheres', subsumindo o racismo ao sexismo e às relações de gênero, tal como compreendido por Davis (2016), feminista negra. Isso significa que as dificuldades enfrentadas cotidianamente adquirem novas tonalidades quando se trata de mulheres negras rurais. De acordo com a Food and Agriculture Organization of the United Nations (FAO, 2017), as mulheres rurais são as que mais vivem em situação de desigualdade social, política e econômica. Em todas as regiões do mundo, enfrentam mais restrições do que os homens no acesso à terra, insumos agrícolas, água, sementes, tecnologia, ferramentas, crédito e assistência técnica. Para mulheres negras e quilombolas, o cenário apresenta-se ainda mais desafiador. 


\section{Gestão do Bolsa Família e Efeitos no Cotidiano de Mulhe- res Quilombolas}

Em relação às formas de gestão, a renda do Bolsa Família tem sido expressivamente direcionada pelas mulheres dos dois estados para a compra de alimentos, cuidado dos filhos e manutenção da casa. Entretanto, o benefício ajuda no pagamento de contas de água, luz e gás e na compra de ração para os animais. Também é utilizado em situações de adoecimento ou de doença crônica, seja na compra de remédios, seja na forma de poupança para atender situações mais graves. É pouco usual que essas mulheres façam uso do recurso para necessidades pessoais, realizando-o geralmente quando há uma 'sobra' do valor, o que raramente acontece.

Não tinha uma renda nem de vinte, nem de trinta reais. Depois veio o Bolsa Família. Só tinha a agricultura. Agora já tem: todo mês eu tenho onde buscar. Já é alguma coisa, melhor do que nada. Às vezes eu tiro vinte, compro uma galinha, compro milho pra uma galinha, compro ração. Compro alguma coisinha, isso aí já é uma mudança. Já é alguma coisa (Entrevistada 1, 25 anos, RN).

O Bolsa Família é considerado pelas participantes como um recurso de apoio para oferecer melhores condições de vida aos filhos. $\mathrm{O}$ acesso ao benefício para algumas mulheres coincidiu com a saída da casa dos pais e sua inserção em uma nova lógica familiar, agora como esposas e mães. Em certas situações, são contempladas pelo benefício ainda na gravidez, tornando-se uma renda fundamental nos primeiros anos de vida da criança, momento que demandam maiores gastos com a prole. Quando os filhos entram na escola, a renda é direcionada para os gastos com materiais escolares, tais como fardamento, materiais de uso em sala, caracterização em datas comemorativas como as festas juninas e lanches.

O benefício representa a principal, senão a única fonte fixa da renda familiar. Apesar de ser um recurso financeiro insuficiente frente às necessidades das mulheres e de suas famílias, particularmente no meio rural, tem demonstrado potência em provocar micro rupturas e reordenamentos nas relações socio comunitárias e nas dinâmicas familiares, alterando o lugar tradicionalmente ocupado pela mulher no cotidiano, a partir da titularidade. Em razão das diferentes histórias de vida e das singularidades nas trajetórias das mulheres em suas famílias, seus impactos têm sido diversos, mas é possível organizá-los nos seguintes âmbitos: relações familiares e conjugais, no acesso a bens de consumo, na tomada de decisão quanto ao manejo da renda e demais aspectos da vida diária e nos modos de trabalho.

No âmbito intrafamiliar, o efeito mais perceptível é a autonomia em relação ao marido, tanto financeiramente, quanto em relação ao poder de decisão na casa. A relativa independência da renda do esposo, bem como a sua não interferência quanto à utilização do BF, provoca alteração na dinâmica familiar estabelecida, na qual era comum precisarem se 'humilhar' e 'pedir' dinheiro aos maridos, até para comprar produtos indispensáveis ao sustento da família e dos filhos. O não ter que 'pedir' também é referenciado em relação à outras pessoas da família como os pais. Logo, o 'não pedir' parece ser um aspecto importante para visualizar os efeitos do BF para essas mulheres:

o bolsa família ele trouxe pra mim, e pra algumas outras mulheres, autonomia de estar dirigindo um recurso que ela achava que nunca iria ter condições de dirigir, ou então nunca ia ter, por que o dinheiro sempre seria do esposo e ele só daria aquele tantinho pra ela fazer a feira no domingo, né? O bolsa família proporcionou isso: eu vou lá no banco, tiro, na casa lotérica eu vou lá e tiro, e é meu. Eu posso fazer o que eu quiser, não preciso estar dando satisfação ao marido pra poder dizer o que é que eu vou comprar ou deixei de comprar, entendeu? (Entrevistada 11, 40 anos, RN).

Assim, o Bolsa Família tem sido reconhecido como um importante disparador da autonomia individual das mulheres e da promoção da equidade de gênero, fornecendo, além da subsistência imediata, uma base material necessária para desenvolver-se em direção a essa autonomia (Bartholo et al., 2019; Rego \& Rego, 2013). Se o cuidado com os filhos e com o lar são funções essencialmente atribuídas às mulheres, afastando-as da possibilidade de desempenhar trabalhos remunerados, conformando sua dependência financeira do marido, ser a titular do BF opera na direção contrária ao instituído no âmbito familiar. As mulheres incrementam seu poder de decisão quanto aos gastos com os filhos e sentem-se orgulhosas de poder cumprir sua função materna, mas de uma outra forma:

(...) depois que o bolsa família chegou na minha vida melhorou bastante, porque assim que eu pude começar a comprar as coisas para os meninos. Um caderno para a escola, que na época era mais difícil, nós não tínhamos como comprar, e eu não tinha como trabalhar porque todo mundo era pequeno, e isso me ajudou muito a comprar um sapato, um chinelo, uma meia, um caderno. Me ajudou muito na renda, não só comprar caderno e essas coisas, mas também na alimentação melhorou bastante, né? Que a gente antigamente não tinha como comprar, mas depois do bolsa família a gente melhorou bastante a alimentação. Começou a manter mais os filhos na escola através da alimentação, que dadas vezes os meninos saíam para a escola sem nem tomar café porque não tinha como tomar café (Entrevistada 11, 40 anos, RN).

Segundo Costa-Fernandez e Munoz (2019), o BF tem sido alvo de críticas por parte de algumas autoras feministas por amparar-se em um "enfoque 'familista' de política pública" (p. 38), reforçando os tradicionais lugares de gênero prescritos às mulheres pela cultura patriarcal. Outros autores apontam o "uso instrumental da mulher" (Bartholo, Passos, \& Fontoura, 2017, p. 12), forma pela qual o Estado objetiva potencializar uma política pública a partir do papel tradicional feminino na família. Desse modo, o valor recebido deveria ser utilizado em favor dos filhos, fazendo cumprir as expectativas sociais sobre o que seria uma 'boa mãe', instituindo certa moralidade na gestão do BF. Esses e outros autores como Rego e Rego (2013), afirmam a existência dessa racionalidade, no entanto, defendem que o benefício abre possibilidades de escape ao futuro como algo cíclico e pré-determinado, contribuindo para minimizar um histórico processo de continuidade e reprodução da pobreza em termos geracionais, particularmente em cenários rurais.

Outra implicação do Bolsa Família consiste na alteração das relações de trabalho remunerado, especialmente em termos da jornada de trabalho dessas mulheres. Segundo uma entrevistada, "Mudei, parei mais de trabalhar nas casas. Porque todo mês eu tenho esse dinheirinho que dá pra ir se mantendo. Não trabalhava como era antes, que era demais, escravidão. É. Trabalhar demais e receber pouco" (Entrevistada 17, 42 anos, $\mathrm{RN}$ ). Ou seja, a renda oriunda do BF contribui para o não assujeitamento a trabalhos precarizados, mal remunerados, insalubres, com longas jornadas e atravessado por relações desiguais de poder, que articulam as iniquidades de gênero, classe e raça.

Ademais, permite que estas mulheres desfrutem de mais tempo livre e consigam se manter no espaço familiar e comunitário, dedicando-se aos trabalhos já desempenhados cotidianamente no lar, no campo e na associação comunitária. Mesmo no caso das mu- 
lheres que trabalham como diaristas fora das comunidades, existe uma preferência por relações menos formais de emprego, posto que percebem a fragilização dos laços socio-comunitários e dos modos de vida no campo quando assumem um posto de trabalho formal. O BF, então, é usado como renda estratégica para trabalhar 'somente o necessário' à sustentação da família no meio rural:

Eu sempre trabalhei, eu sempre trabalhei fora. Trabalhei em Natal, sempre fiz faxina em Natal. Então assim, não é porque eu recebi o bolsa família que eu deixei de fazer isso, continuo fazendo do mesmo jeito. Pronto, eu não estou trabalhando hoje, porque eu não quero. Por exemplo, as faxinas, eu trabalhava três dias por semana. Eu deixei, e vim pra casa. A mulher ligou pra mim ontem: - "venha fazer uma faxina aqui em casa"; - "Mulher, não posso não. Já tenho serviço demais por aqui" (Entrevistada 23, 38 anos, RN).

Assim, os efeitos do BF no trabalho remunerado vão na direção contrária ao que é defendido por alguns autores, os quais temem que programas de transferência monetária induzam à uma redução na oferta de trabalho e do o emprego formal. Essa suposta acomodação tem sido tratada na literatura por "efeito preguiça" (D. B. Santos, Leichsenring, \& Filho, 2017, p. 709), endossa o estereótipo do 'pobre preguiçoso' à espera de ações assistencialista por parte do Estado.

Essa lógica desconsidera questões fundamentais como a forte presença de mulheres em ocupações precárias, como é o caso das empregadas domésticas e daquelas que trabalham para o próprio consumo e o consumo familiar, principalmente no setor agrícola (Neves, 2013); os trabalhos desvalorizados socialmente que acumulam múltiplas desigualdades sociais - de classe, de gênero e de raça -, os quais impõem dificuldades para conciliar o trabalho doméstico remunerado com o trabalho doméstico não pago (Sorj, 2014); a alta concentração de renda e consequente conjugação de uma massa de trabalhadores destituída de recursos materiais e dispostas a vender sua mão de obra (Bernardino-Costa, 2015); a posição das mulheres, ainda profundamente marcada pela marginalização e inferiorização recorrentes das ocupações tipicamente 'femininas', de menor remuneração e menor status, e do salário inferior ao dos homens nas mesmas funções, profissões e níveis educacionais (Biroli, 2015).

Porém, diversamente das análises de cunho moral, observa-se que o BF é uma ferramenta que permite às mulheres escolher, minimamente, os tipos de atividades e quanto de tempo deve dedicar a cada uma delas e, em função disso, funciona como dispositivo de insubordinação às opções precárias de trabalho designadas às mulheres e às pessoas negras, por gerações. Além disso, para as mulheres como as de nosso estudo, poder permanecer no campo é uma conquista, pois habitar um território rural implica particulares formas de vida, visões de mundo e definições da própria subjetividade. O trabalho no campo, as diversas atividades rurais, são fonte fundamental de reconhecimento social, orgulho e configuração das subjetividades das mulheres. O trabalho, como uma 'forma de vida', se transforma no eixo articulador dos costumes e atividades na família rural (Costa-Fernandez \& Munoz, 2019, p. 39).

Para além de um dispositivo de insubordinação ao trabalho precarizado, o BF reverbera também na forma de usar o benefício. Em primeiro lugar, porque resulta no aumento do poder de compra e de acesso a bens de consumo não duráveis/de consumo imediato, semiduráveis e, em poucos casos, duráveis. Em segundo lugar, porque funciona como suporte financeiro, sobretudo, nas situações de desemprego do cônjuge ou quando este desempenha trabalhos temporários - os chamados 'bicos' -, e de modo geral, um apoio para 'não passar necessidade' e 'não pedir nada a ninguém'. Isso demonstra o quanto tem contribuído para ampliar as possibilidades de escolhas individuais das mulheres, mesmo que precisem recuar em tempos de insegurança financeira.

Por exemplo, chega no fim do mês, que eu recebo meu bolsa família, aí meu marido não tem ganhado um dia de serviço. Aí eu venho fazer uma feira, né? Pra não faltar nada dentro de casa. Fazer uma feira não, que ninguém não faz feira. A gente faz é um quebra galho. Aí vem uma luz pra pagar, já tira um pedacinho dali, bota ali, que eu vou ganhar um dia de serviço acolá, se aparecer, a gente já bota ali, dá pra pagar uma luz (Entrevistada 21, 35 anos, RN).

Em terceiro e último lugar, já que a titularidade é preferencialmente atribuída às mulheres, o $\mathrm{BF}$ é um recurso que é gerido por elas próprias. Como muitas apontam: antes de serem vinculadas ao programa, o manejo da renda era realizado somente pelo esposo, o qual definia em que deveria ser gasto. Agora, com o 'dinheiro na mão', sentem mais autonomia para interferir na definição e organização dos gastos familiares, posto que há o entendimento na família que o BF é uma renda da mulher:

Eu me sinto bem. Vem mais no meu nome, oia! Imagina, pega o cartãozinho e vou lá passando:- "É seu?"; - “É, tá aqui, é meu!’. Entendeu? Eu me sinto bem! Me faz bem. Porque eu deixo todinho lá, logo, de uma vez. Pago a água, pago a luz, pronto. Oitenta e cinco reais, mas é uma ajuda muito grande e eu me sinto bem porque pelo menos tá no meu nome, né? Alguma coisa no meu nome (Entrevistada 37, 20 anos, PI).

O estudo realizado por Rego e Rego (2013) aponta resultado semelhante quanto aos sentimentos vivenciados pelas mulheres: de dignificação, confiabilidade, respeitabilidade, auto respeito e de reconhecimento por parte de instituições políticas do Estado. Em um cenário onde as famílias precisam desenvolver múltiplas estratégias de complementação de renda, o BF representa uma das poucas rendas fixas da casa, aportando uma certa segurança. Segundo Costa-Fernandez e Munoz (2019), além da valorização feminina, a experiência de um "quase salário" (p. 40) oferece, minimamente, às suas titulares a possibilidade de planejamento das despesas familiares.

Por fim, apenas sete mulheres afirmam não sentirem efeitos diretos em seu cotidiano em função do BF. Explicam que, acrescido ao fato de que o benefício consiste em uma renda com poucas possibilidades de manejo devido às condicionalidades, continuam fazendo as mesmas atividades e no mesmo ritmo que faziam antes de receber o recurso. Esse cenário nos leva a pensar que em algumas situações, as relações familiares, engendradas intergeracionalmente, pouco têm se alterado com a chegada do programa, estando menos porosas às mudanças nos lugares tradicionais de gênero. Contudo, de uma forma geral, no que tange aos efeitos provocados pelo $\mathrm{BF}$ no cotidiano de mulheres moradoras de comunidades quilombolas rurais, nota-se que muitos aspectos das suas vidas foram afetados, ampliando os gradientes de autonomia e independência, seja na tomada de decisão quanto ao uso do recurso, seja na possibilidade de escolha das atividades laborais que permitem uma melhor qualidade de vida, seja em termos de autoestima e de capacidades para enfrentar as desigualdades de gênero e o papel tradicional feminino na família.

\section{Considerações Finais}

Este estudo não teve a pretensão de traçar generalizações acerca dos efeitos do Bolsa Família para suas beneficiárias, nem seria possível tal consensualidade, em função da diversidade dos 
sujeitos e contextos alcançados pelo programa. De acordo com a Secretaria de Avaliação e Gestão da Informação (SAGI, 2020), existem atualmente no país mais de 14 milhões de famílias beneficiárias, dentre as quais, 135.785 são famílias quilombolas. Sabendo-se que mais de $92 \%$ das mulheres têm a titularidade, é possível dimensionar a limitação desse estudo e a necessidade de mais investimento em pesquisas voltadas à avaliação qualitativa da gestão do benefício e seus impactos na vida dessas mulheres.

No entanto, de forma situada e localizada, produzimos canais dialógicos para dar voz às mulheres quilombolas rurais ao tratarem do seu cotidiano de trabalho, das experiências com o BF e seus efeitos em diferentes dimensões de suas vidas. As atividades que envolvem o trabalho doméstico e de cuidado permanecem sendo desenvolvidas, prioritariamente, pelas mulheres. No entanto, além dessas atividades, os trabalhos que realizam no roçado, no cuidado com os animais, como faxineiras na cidade, na cooperativa, no extrativismo, no pequeno comércio domiciliar, demonstraram que o trabalho feminino é fundamental à sobrevivência familiar no meio rural. Apesar dessa participação ativa das mulheres na subsistência e na organização familiar, foi apenas com a chegada do Bolsa Família que passaram a se sentir mais autônomas e ter reconhecimento em termos da organização e sustento familiar. Com isso, foram deflagrados inúmeros processos de subjetivação e de reconfiguração dos lugares de gênero nas relações familiares. Esses deslocamentos, que emergiram nos discursos das mulheres, representam importante contribuição acerca dos efeitos psicossociais do Bolsa Família na vida de mulheres rurais.

\section{Referências}

Alves, J. M. P. M. (2014). «O que eu faço tem valon»: discutindo o cuidado familiar e o reconhecimento. Ex aequo, 30, 97-111. Recuperado de http://www.scielo.mec.pt/scielo.php?script=sci arttext\&pi$\mathrm{d}=$ S0874-55602014000200008\&lng $=\mathrm{pt} \& \mathrm{t} \operatorname{lng}=\mathrm{pt}$

Arrais, T. A. (2016). O Bolsa Família e a tradução regional da questão social. Revista do Instituto de Estudos Brasileiros, 65, 200-226. https://doi.org/10.11606/ issn. 2316-901x.v0i65p200-226

Bartholo, L., Passos, L., \& Fontoura, N. (2019). Bolsa Família, autonomia feminina e equidade de gênero: o que indicam as pesquisas nacionais? Cadernos Pagu, 55, e195525. https://doi.org/10.1590/18094449201900550025

Bartholo, L., Passos, L., \& Fontoura, N. (2017). Bolsa Família, Autonomia Feminina e Equidade de Gênero: o que indicam as pesquisas nacionais? Rio de Janeiro: IPEA. Recuperado de http://repositorio.ipea.gov.br/bitstream/11058/8051/1/td 2331.PDF

Bernardino-Costa, J. (2015). Colonialidade e interseccionalidade emancipadora: a organização política das trabalhadoras domésticas no Brasil. Sociedade e Estado, 30(1), 147-163. https://doi.org/10.1590/S0102-69922015000100009

Biroli, F. (2015). Responsabilidades, cuidado e democracia. Revista Brasileira de Ciência Politica, 18, 81-117. https://doi.org/10.1590/0103-335220151804

Biroli, F. (2018). Gênero e desigualdades: os limites da burocracia no Brasil. São Paulo: Boitempo.

Food and Agriculture Organization of the United Nations (2017). A importancia das mulheres rurais no desenvolvimento sustentável do futuro. Recuperado de https:// nacoesunidas.org/artigo-a-importancia-das-mulheres-rurais-no-desenvolvimento-sustentavel-do-futuro/

Chaves, A., Castro, R., \& Portugal, A. (2018). A busca pela ascensão feminina no PDS Virola Jatobá, Anapu-PA. Revista Estudos Feministas, 26(1). https://doi. $\operatorname{org} / 10.1590 / \%$ x

Costa-Fernandez, E., \& Munoz, C. A. B. (2019). Subjetividades de beneficiárias do Programa Bolsa Família em contexto rural. Fractal: Revista de Psicologia, 31(1), 35-42. https://doi.org/10.22409/1984-0292/v31i1/5581

Dantas, C. M. B., Dimenstein, M., Leite, J. F., Torquato, J., \& Macedo, J. P. (2018). A pesquisa em contextos rurais: desafios éticos e metodológicos para a psicologia. Psicologia \& Sociedade, 30, e165477. https://doi.org/10.1590/ 1807-0310/2018v30165477

Davis, A. (2016). Mulheres, raça e classe. São Paulo: Boitempo.

Dimenstein, M., Belarmino, V., Leite, J., Macedo, J., Silva, I., Dantas, C., \& Alves Filho, A. (2018). Consumo de álcool em uma comunidade quilombola do nordeste brasileiro. Quaderns De Psicologia, 21(1), e1479. https://doi. org/10.5565/rev/qpsicologia.1479

Dimenstein, M., Leite, J., Macedo, J. P., \& Dantas, C. (2016). Condições de vida e saúde mental em contextos rurais. São Paulo: Intermeios.
Diniz, R. (2017). Hoje tem festa na roça: o trabalhar-festar das marombas e a espaço-temporalidade da cultura afro-brasileira em territórios quilombolas do Vale do Jequitinhonha mineiro. Raega - O Espaço Geográfico em Análise, 42, 36-53. Recuperado de https://revistas.ufpr.br/raega/article/view/44648

Fernandes, T, \& Mota, D. M. (2014). "É sempre bom ter o nosso dinheirinho": sobre a autonomia da mulher no extrativismo da mangaba no Pará. Revista de Economia e Sociologia Rural, 52(1), 9-24. https://doi.org/10.1590/S010320032014000100001

Instituto Brasileiro de Geografia e Estatística (2018). Sintese de indicadores sociais: uma análise das condiçoes de vida da população brasileira: 2018. Rio de Janeiro: Autor. Recuperado de https://biblioteca.ibge.gov.br/index.php/biblioteca-catalogo? view $=$ detalhes\&id $=2101629$

Lago, M. C. S., Souza, C. D., Kaszubowski, E., \& Soares, M. S. (2009). Gênero, gerações e espaço doméstico: trabalho, casa e família. Paidéia (Ribeirão Preto), 19(44), 357-366. https://doi.org/10.1590/S0103-863X2009000300010

Maciazeki-Gomes, R. C., Nogueira, C., Vázquez, C. L., \& Toneli, M. J. (2016). Participação política e subjetividade - Narrativas de vida de trabalhadoras rurais do sul do Brasil. Psico, 47(2), 148-158. https://doi. org/10.15448/1980-8623.2016.2.21933

Minayo, M. C. S., \& Sanches, O. (1993). Quantitativo-qualitativo: oposição ou complementaridade? Cadernos de Saúde Pública, 9(3), 237-248. https://doi. org/10.1590/S0102-311X1993000300002

Minayo, M. C. S. (2010). O desafio do conhecimento: pesquisa qualitativa em saúde. São Paulo: HUCITEC.

Montenegro, I. M., \& Leiva, M. B. (2017). Enfoques de género en el papel de la mujer rural en la agricultura cubana. Prolegómenos. Derechos y Valores, XX(39), 29-38. Recuperado de https://www.redalyc.org/articulo. oa?id $=876 / 87650862003$

Neri, E. L., \& Garcia, L. G. (2017). Atrizes da roça ou trabalhadoras rurais? O teatro e a fachada para obtenção da aposentadoria especial rural. Sociedade e Estado, 32(3), 701-724. https://doi.org/10.1590/s0102-69922017.3203007

Neves, M. A. (2013). Anotações sobre trabalho e gênero. Cadernos de Pesquisa, 43(149), 404-421. https://doi.org/10.1590/S0100-15742013000200003

Paulilo, M. I. (2016). Mulberes rurais: quatro décadas de diálogo. Florianópolis: Ed. da UFSC.

Pinheiro, F. D., \& Maia, L. S. (2017). Cativas do corpo, libertas pelo trabalho: casos de mulheres de cor nas fronteiras entre escravidão e liberdade (Mariana, séculos XVIII e XIX). Cadernos Pagu, 50, e175011. https://doi.org/10.1590/ 18094449201700500011

Quijano, A. (2005). Colonialidade do poder, eurocentrismo e América Latina. CLASCO.

Rego, W. L., \& Rego, A. P. (2013). Vozes do Bolsa Familia: autonomia, dinheiro e cidadania. São Paulo: Editora Unesp.

Ribeiro, F. G., Shikida, C., \& Hillbrecht, R. O. (2017). Bolsa Família: Um survey sobre os efeitos do programa de transferência de renda condicionada do Brasil. Estudos Econômicos (São Paulo), 47(4), 805-862. https://doi. org/10.1590/0101-416147468fcr

Secretaria de Avaliação e Gestão da Informação (2020). Relatório sobre Bolsa Família e Cadastro único. Brasília: autor. Recuperado de http:// aplicacoes.mds.gov.br/sagi/RIv3/geral/relatorio form.php?p ibge=\&area $=0$ \&ano pesquisa $=\&$ mes pesquis $a=\&$ said $a=$ pdf\&relatorio $=153 \&$ $\mathrm{ms}=623,460,587,589,450,448 \#: \sim$ :text $=0 \% 20$ Programa $\% 20 \mathrm{Bolsa} \% 20 \mathrm{Fa}-$ m\%C3\%ADlia $\% 20$ (PBF, $111.249 \% 2 \mathrm{C} 00 \% 20 \mathrm{no} \% 20 \mathrm{~m} \% \mathrm{C} 3 \%$ AAs

Santos, D. B., Leichsenring, A. R., Filho, N. M., \& Mendes-Da-Silva, W. (2017). Os efeitos do Programa Bolsa Família sobre a duração do emprego formal dos indivíduos de baixa renda. Revista de Administração Pública, 51(5), 708733. https://doi.org/10.1590/0034-7612171851

Santos, M. C. S., Delatorre, L. R., Ceccato, M. G. B., \& Bonolo, P. F. (2019). Programa Bolsa Família e indicadores educacionais em crianças, adolescentes e escolas no Brasil: revisão sistemática. Ciência es Saúde Coletiva, 24(6), 22332247. https://doi.org/10.1590/1413-81232018246.19582017

Senicato, C., Lima, M. G., \& Barros, M. B. A. (2016). Ser trabalhadora remunerada ou dona de casa associa-se à qualidade de vida relacionada à saúde? Cadernos de Saúde Pública, 32(8), e00085415. https://doi.org/10.1590/ 0102-311X00085415

Silva, M. R. S., Luz, G. S., Cezar-Vaz, M. R, \& Silva, P. A. (2012). Trabalho familiar: distribuição desejada do trabalho doméstico e cuidados dos filhos entre cônjuges. Revista Gaúcha de Enfermagem, 33(1), 124-131. https://doi. org/10.1590/S1983-14472012000100017

Sorj, B. (2014). Socialização do cuidado e desigualdades sociais. Tempo Social, 26(1), 123-128. https://doi.org/10.1590/S0103-20702014000100009

Wolf, M. R., \& Barros, A. A. (2014). Estado nutricional dos beneficiários do Programa Bolsa Família no Brasil: uma revisão sistemática. Ciência \& Saúde Coletiva, 19(5), 1331-1338. https://doi.org/10.1590/1413$\underline{81232014195.05052013}$ 
Informações sobre os autores:

\section{Antonio Alves Filho}

Av. Gandhi, 1327. Nova Parnamirim - Parnamirim - RN, Brasil, CEP 59152-780.

E-mail: antonioalvesfil@gmail.com

\section{Magda Dimenstein}

E-mail: mgdimenstein@gmail.com

Victor Hugo Belarmino

E-mail: victorbelarmino@outlook.com

\section{Jáder Ferreira Leite}

E-mail: jaderfleite@gmail.com

\section{Candida Dantas}

E-mail: candida.dantas@gmail.com

\section{João Paulo Macedo}

E-mail: jampamacedo@gmail.com 